\title{
A produção institucional na perspectiva arquivística - lei de acesso à informação e aproximações
}

\author{
Gilberto Fladimar Rodrigues Viana* \\ Telma Campanha de Carvalho Madio ${ }^{* *}$
}

\begin{abstract}
Resumo Este trabalho trata da aplicação da lei de acesso à informação, na perspectiva arquivística da produção institucional dos projetos registrados no período de 1992 a 2012, no Centro de Artes e Letras (CAL) da Universidade Federal de Santa Maria (UFSM), e armazenada em suporte digital no banco de dados da instituição. Conclui-se que os efeitos da lei de acesso às informações, com relação à produção institucional da UFSM, trarão benefícios a toda a sociedade.
\end{abstract}

Palavras chave Produção institucional. Arquivistica. Lei de acesso à informação. Documentos digitais. Pós-custodial.

\section{Institutional production from an archivistic perspective - the Law of Access to Information}

\begin{abstract}
This study regards the implementation of the Law of Access to Information, from an archivistic perspective of the institutional production of recorded projects in the period 19922012 at the Letters and Arts Center (LAC) of the Federal University of Santa Maria (UFSM) and stored on digital medium in its database. It concludes that the effects of the law of access to information, as related to the institutional production by UFSM, will bring benefits to all society.
\end{abstract}

Keywords Institutional Production; Archival Science; Law of Access to Information; Digital Document; Post-Custodial.

\section{Introdução}

Este trabalho tem como objetivo apresentar o quadro da Arquivologia e de tópicos que tangenciam a Lei de Acesso à Informação (LAI), Lei $\mathrm{n}^{\circ}$ 12.527, com relação aos documentos

\footnotetext{
*** Doutorando do Programa de Pós-Graduação em Ciência da Informação. Universidade Estadual Paulista Júlio de Mesquita Filho/UNESP. Endereço: Rua Waldemar Kireff, 71 - apt. 12, Jardim Araxá - 17525-050 - Marília - SP. E-mail: vrfgpc@gmail.com

** Doutora/professora da Universidade Estadual Paulista Júlio de Mesquita Filho/UNESP, do Departamento de Ciência da Informação da Faculdade de Filosofia e Ciências e do Programa de Pós-Graduação em Ciência da Informação - Campus Marília. Endereço: Avenida Hygino Muzzi Filho, 737 - 17525-900 - Marília - SP. Telefone: (14) 3402-1370. E-mail: telmaccarvalho@ marilia.unesp.br
} 
arquivísticos digitais, assim como referenciar normas relacionadas aos referidos documentos, tendo como base de aplicação o banco de dados de projetos do Centro de Artes e Letras, que faz parte da produção institucional da Universidade Federal de Santa Maria - UFSM.

Esse banco de dados, no módulo projeto (sistema de registro de projetos), integra o Sistema de Informações para o Ensino - SIE, cujo módulo foi criado em 1992, permanecendo em pleno funcionamento.

A situação dos documentos arquivísticos digitais é uma temática recente e que envolve, primordialmente, a atuação dos profissionais arquivistas, assim como dos profissionais que atuam especificamente na área de informática e, também, dos dirigentes de uma organização. Conforme ICA 16 (2005, p. 30): "Os arquivistas devem trabalhar em conjunto com gestores dos sistemas que suportam o desenvolvimento de normas transversais na administração para a interoperabilidade de sistemas, a normalização da gestão da informação e outras iniciativas similares".

Essa atuação mostra-se necessária na medida em que as organizações se deparam com um volume elevado de informações arquivísticas em seus bancos de dados e esses não podem prescindir de um tratamento adequado através de normas e recomendações.

Nesse contexto, os documentos arquivísticos digitais são de extrema importância para a instituição (UFSM), razão pela qual convém que seus dirigentes estejam atentos, dispensando a essa questão um tratamento adequado, voltado à preservação de seu patrimônio documental, neste caso, o banco de dados do sistema de registro de projetos que faz parte do SIE, assim considerado, pois, conforme Constituição Federal de 1988, em seu artigo 216:

Constituem patrimônio cultural brasileiro os bens de natureza material e imaterial, tomados individualmente ou em conjunto, portadores de referência à identidade, à ação, à memória [...] III - as criações científicas, artísticas e tecnológicas; IV - as obras, objetos, documentos, edificações e demais espaços destinados às manifestações artístico culturais; V - os conjuntos urbanos e sítios de valor histórico, paisagístico, artístico, arqueológico, paleontológico, ecológico e científico (BRASIL, 1988).

Analisando-se sob o enfoque arquivístico a Lei de Acesso à Informação (LAI 12.527), que regulamenta o acesso à informação, assinala-se que, por trabalhar-se o referido enfoque, substituir-se-á a expressão "documento" pela expressão "informação". O inciso XXXIII do art. $5^{\circ}$ trata das garantias de direitos individuais e coletivos do cidadão de receber informações dos órgãos públicos; o inciso II do $3^{\circ} \S$ do art. 37 disciplina o acesso dos usuários a informações dos órgãos públicos; no $2^{\circ} \S$ do art. 216, tem-se como um dos princípios a "universalização do acesso aos bens e serviços culturais", esses, por sua vez, da Constituição da República Federativa do Brasil de 1988. Conjuntamente, analisa-se o decreto que trata as informações sigilosas, Decreto $\mathrm{n}^{\mathrm{o}} 7.845$, e a Lei $\mathrm{n}^{\mathrm{o}}$ 8159, sobre a Política Nacional de Arquivos. Discorre-se, também, sobre normas que tangenciam a consistência das informações arquivísticas relativas à segurança através da série da ISO 30300, bem como questões do pós-custodial e da curadoria digital.

Conclui-se que esse banco de dados deve ser preservado como fonte de informações arquivísticas dignas de crédito e tratadas adequadamente, conforme a legislação, o regramento e 
as normatizações específicas explicitadas neste texto e em outros estudos dirigidos ao tema do acesso a informações de instituições de ensino, pesquisa e extensão.

\section{Síntese dos números sobre projetos}

Faz-se necessário contextualizar a questão da produção institucional da UFSM, referente aos projetos registrados no SIE, no período de 1992 a 2012, do Centro de Artes de Letras, conforme os gráficos 1 e 2 .

Considerando os dados quantitativos coletados no sistema e a dinâmica de tabulação, passa-se a descrevê-los em gráficos e suas respectivas análises, à luz da realidade constatada ao longo do funcionamento do sistema.

Tem-se, inicialmente, no gráfico 1, os dados quantitativos totais dos projetos por situação: em andamento, cancelado, concluído e suspenso, considerando o período compreendido entre 1992 e 2012, com um total de 1639 projetos.

Gráfico 1: Total de projetos registrados no período 1992/2012, por situação.

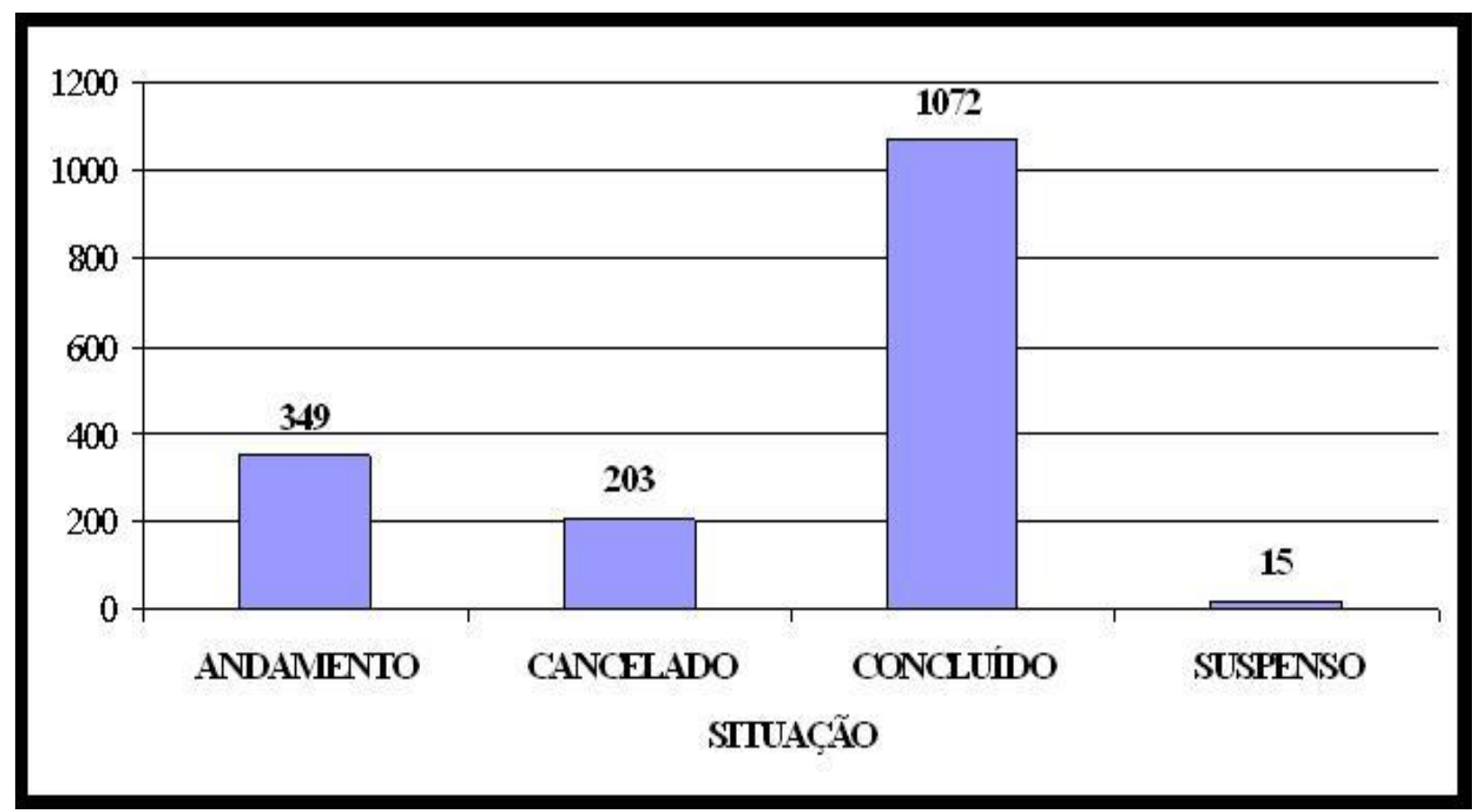

Fonte: SIE/UFSM

No gráfico 1, constata-se o expressivo número de projetos concluídos em $70 \%$ e, em andamento, cerca de $21 \%$ sobre o total de projetos registrados. Tais percentuais estão associados à observância por parte dos coordenadores de projetos e das repercussões que eles trazem para 
fins: a) orçamentários, uma vez que o número de projetos é utilizado como indicador de divisão orçamentária entre as unidades universitárias (Centro) e as subunidades do Centro (coordenações e departamentos); b) de progressão funcional dos docentes; de seu próprio projeto, tendo em vista o recebimento de financiamento para o seu desenvolvimento, acarretando a demanda por uma avaliação anual.

No gráfico 2 são expostos os quantitativos totais dos projetos por tipo: ensino, extensão, pesquisa e outros, considerando o período 1992/2012, com um total de 1639 projetos.

Gráfico 2: Total de projetos registrados no período 1992/2012, por tipo.

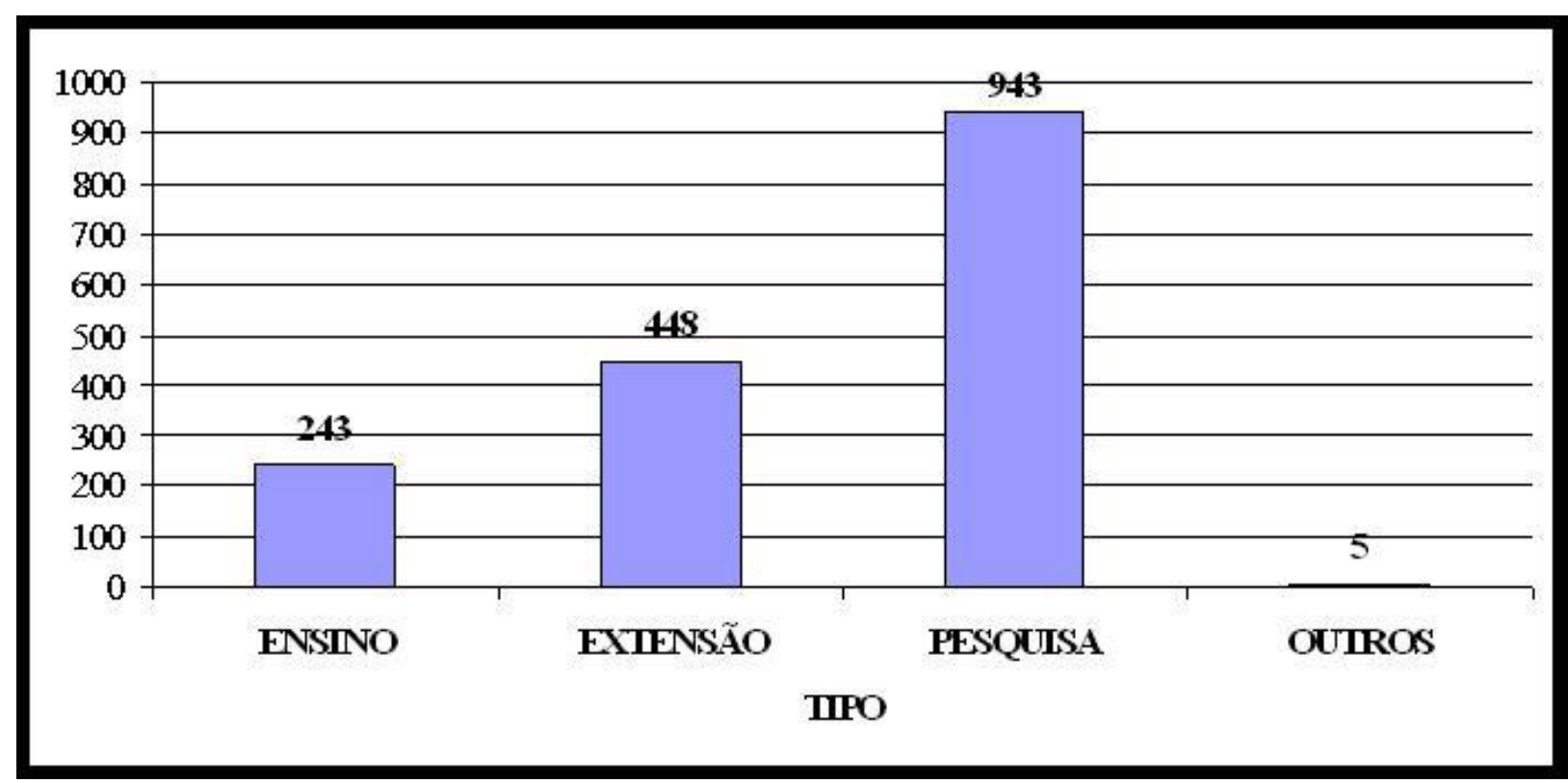

Fonte: SIE/UFSM

Conforme o gráfico 2, constatam-se os números expressivos de projetos do tipo pesquisa e extensão, representando, respectivamente, cerca de $55 \%$ e $30 \%$ sobre o total de projetos. Cabe destacar que ambos contam com financiamento interno considerável, tanto quanto de fontes financiadoras externas, como do Conselho Nacional de Desenvolvimento Científico e Tecnológico - CNPq e da Fundação de Amparo à Pesquisa do Estado do Rio Grande do Sul FAPERGS-, direcionadas à pesquisa, e o Programa de Extensão Universitária - ProExt -, direcionado à extensão.

Enfatizam-se, também, os projetos do tipo pesquisa compostos por projetos de monografias, de especialização, de dissertação e de tese, orientados por professores lotados no Centro em programas de pós-graduação do referido Centro. Os projetos do tipo ensino, por sua vez, contam com financiamentos internos, porém pouco expressivos.

A partir dos dados quantitativos pertinentes aos projetos do CAL, passa-se a relacioná-los à LAI e também a abordagens que dizem respeito a estudos e normativas como suporte teórico à arquivística, considerando: o acesso, a segurança e a atuação profissional do arquivista na era 
pós-custodial, funções da curadoria digital e também as responsabilidades dos agentes públicos e, por extensão, do profissional arquivista em relação ao acesso às informações à sociedade.

\section{A arquivística e suas implicações para a lei de acesso à informação: aproximações}

Inicialmente, destaca-se o que Bellotto diz sobre fundo de arquivo:

É um universo arqueológico a identificar, balizar, ordenar, descrever e analisar de modo a possibilitar a preservação de sua organicidade, de sua integridade física, e a disseminação de informações extraídas de seus elementos, colocandoas em condições de apreensão e uso plenos (BELLOTTO, 2007, p.13).

Um estudo que se destaca é o de Jardim (1995), autor que discorre sobre o universo de atuação dos profissionais arquivistas em relação a um Sistema Nacional de Arquivos no Brasil, em que se vislumbra o estado da arte da atuação desses profissionais: "Neste palco nem sempre iluminado, uma categoria profissional ainda emergente, a dos arquivistas, é o principal ator, quase um figurante, contido e perifericamente situado nesta cena" (JARDIM, 1995, p.73).

A partir do que dizem Bellotto e Jardim, passa-se a considerar o enfoque arquivístico em relação às informações arquivísticas dos registros e alterações de projetos no SIE, do CAL.

Para discorrer sobre a função arquivística, tomou-se por base o conceito assim expresso: "A função arquivística é o conjunto de atividades relacionadas que contribuem e são necessárias para cumprir os objetivos de salvaguarda e preservação de documentos de arquivos definitivos e assegurar que esses documentos são acessíveis e inteligíveis” (ICA 16, 2005, p.11).

A função arquivística, porém, é mais abrangente do que aqui expresso, visto que, na atualidade, o arquivista e os profissionais que trabalham com documentos em suporte digital se deparam com uma situação já na fase de produção dos documentos, ou seja, no planejamento do sistema de arquivo que, por sua vez, tem como missão garantir a manutenção e a preservação dos documentos, em termos de autenticidade, fidedignidade e acessibilidade, no decorrer do ciclo de vida documental. Somam-se a essas características a integridade do documento, assim como sua utilização.

Consideram-se, em relação às funções arquivísticas, algumas divergências no que se refere a que momento essas funções devam ser aplicadas. Leva-se em conta, como ponto inicial, o ciclo de vida dos documentos ou a teoria das três idades: primeira fase - arquivo corrente -, que se caracteriza pela utilização frequente dos documentos, sendo que esses documentos sempre devem estar acessíveis para o bom andamento das atividades da instituição; segunda fase arquivo intermediário -, que se caracteriza por ser consultado eventualmente. A guarda de documentos atende a necessidades ou exigências legais, administrativas ou financeiras, podendo o acervo estar afastado da instituição. Cabe enfatizar que ambas as fases, a primeira e a segunda, são consideradas de valor primário. Já a terceira fase - arquivo permanente - é considerada de 
valor secundário, uma vez que a documentação poderá ser eliminada ou recolhida ao arquivo permanente, caracterizando-se como uma documentação de valor histórico.

Nesse sentido, resgata-se o que diz Schellenberg (1974, p.19), ao alegar que, para serem documentos de arquivo, "os documentos devem ter sido produzidos ou acumulados na consecução de um determinado objetivo e possuir valor para fins outros que não aqueles para os quais foram produzidos ou acumulados".

Quanto à definição de arquivo, Paes (1997, p.16) o conceitua como: “[...] a acumulação ordenada de documentos, em sua maioria textuais, criados por uma instituição ou pessoa, no curso de sua atividade, e preservados para a consecução de seus objetivos, visando à utilidade que poderão oferecer no futuro".

Em relação às classificações dos arquivos, esses podem ser considerados: quanto à entidade mantenedora: público ou privada; quanto à dimensão de sua atuação: setorial ou central; quanto à evolução: corrente, intermediário ou permanente; e quanto à natureza: especial ou especializado. No presente trabalho, aborda-se o enfoque arquivístico do sistema de registro de projetos que faz parte do banco de dados da UFSM.

A UFSM, como órgão público, está sujeita à Lei no 12.527 (Lei de acesso à informação - LAI) que estabelece como fundamento o princípio de que o acesso à informação pública é a regra, e o sigilo, a exceção. Assim sendo, quanto à natureza do assunto, tem-se o ostensivo (regra) e o sigiloso (exceção). Quanto ao sigilo, conforme o artigo $24, \S 1^{\circ}$, as informações podem ser classificadas como: reservada, secreta e ultrassecreta, pelo período de 5, 15 e 25 anos respectivamente, a partir de sua produção. Conforme o artigo $27^{\circ}$ da Lei $n^{\circ} 12.527$, a informação será considerada sigilosa de acordo com a necessidade de segurança e "imprescindível para a segurança da sociedade e do Estado" e definida pela autoridade máxima da instituição pública que detém essa informação.

Também destaca-se que, na Lei $\mathrm{n}^{\mathrm{o}} 12.527$, é revogado, na íntegra, o capítulo $\mathrm{V}$, que tratava do acesso e do sigilo de documento público da Lei $n^{\circ} 8.159$ (política nacional de arquivos públicos e privados).

Ainda quanto ao sigilo, enfatiza-se o Decreto $\mathrm{n}^{\circ} 7.724$, que regulamenta a Lei $\mathrm{n}^{\circ} 12.527$ no artigo 32, onde determina que a autoridade que classificar uma informação como sigilosa deverá encaminhar cópia do Termo de Classificação de Informação - TCI - à Comissão Mista de Reavaliação de Informações (composta por representantes do primeiro escalão do poder executivo). Conforme o artigo 46, esse decreto também propõe que os órgãos públicos constituam a sua Comissão Permanente de Avaliação de Documentos Sigilosos - CPADS -, essas com caráter consultivo.

Associam-se às funções arquivísticas: produção, avaliação, aquisição, conservação, classificação, descrição e difusão. $\mathrm{Na}$ LAI, em seu artigo $4^{\circ}$, inciso V, têm-se definições peculiares e importantes que também dizem respeito ao fazer arquivístico. São elas: "tratamento da informação: conjunto de ações referentes à produção, recepção, classificação, utilização, acesso, reprodução, transporte, transmissão, distribuição, arquivamento, armazenamento, eliminação, avaliação, destinação ou controle da informação; I - informação: dados, processados ou não, que podem ser utilizados para produção e transmissão de conhecimento, contidos em qualquer meio, suporte ou formato; II - documento: unidade de registro de informações, qualquer que seja o suporte ou formato". 
Com relação a essas considerações sobre as funções arquivísticas e as definições relativas ao "tratamento da informação", conforme a LAI, constata-se que devem ser tratadas no contexto arquivístico. Ambas são consideradas muito importantes, destacando-se em especial para esta análise a função de avaliação, que define o valor do documento, se primário ou secundário, dentro do ciclo de vida do documento. Outra função que também se destaca é a classificação, onde o princípio elementar é o da proveniência e o da ordem original.

Corroborando com o princípio da proveniência, destaca-se que a linguagem documentária também dá sustentação, visto que a organicidade implica em seguir um objetivo, a ordem original e, daí, a hipótese que respondam a esses objetivos, conforme explicitado por Lara (2001):

[...] uma linguagem documentária que será utilizada para "representar conteúdos" não pode ser formulada a partir de opiniões ou referências particulares e isoladas. Ao contrário, se o objetivo dos sistemas documentários é transmitir informação, tais linguagens devem ser organizadas a partir de hipóteses que façam sentido para determinados objetivos (LARA 2001, p.8).

A difusão e o acesso também são funções que fazem parte do tratamento da informação, conforme a LAI; de igual forma, são importantes e, em particular, no caso da UFSM, seu banco de dados comporta um grande volume e uma gama de diversidade de informações arquivísticas que fazem parte da vida da instituição.

Além das características supracitadas, com relação às funções arquivísticas, também conforme ICA 16 (2005), duas outras são consideradas muito importantes: a sua autenticidade - significa que o documento de arquivo é o que pretende ser, e a sua fidedignidade - servir de prova digna de crédito. Associam-se às características de documento de arquivo, já citadas, as considerações conceituais da LAI, no artigo $4^{\circ}$, inciso VI, quanto à "autenticidade: qualidade da informação que tenha sido produzida, expedida, recebida ou modificada por determinado indivíduo, equipamento ou sistema"; inciso VIII, "a integridade: qualidade da informação não modificada, inclusive quanto à origem, trânsito e destino"; inciso IX, "a primariedade: qualidade da informação coletada na fonte, com o máximo de detalhamento possível, sem modificações”. Quanto à autenticidade, pode-se dizer que o documento deverá manter suas características originais quanto ao contexto, à estrutura e ao conteúdo, sendo isso definido como coerência, com o fim para o qual o documento foi criado.

Uma contribuição teórica que pode colaborar para o melhor entendimento da questão sobre autenticidade de documentos enquanto objecto digital é apresentada por Ferreira (2006), ao alegar que:

Para atingir esse objectivo é fundamental documentar devidamente a proveniência do objecto, contextualizar a sua existência, descrever a sua história custodial e atestar que a sua integridade não foi comprometida, i.e. provar que existe um conjunto de propriedades, consideradas significativas, que foram correctamente preservadas ao longo do tempo (FERREIRA, 2006, p.50).

Dessa forma, os metadados podem ser úteis sob vários aspectos que envolvam os documentos de 
arquivo eletrônicos, pois fornecem informações arquivísticas sobre a produção do documento. Constituem um detalhamento de todas as modificações/alterações procedidas no documento, ou seja, apresentam informações arquivísticas contextuais sobre as atividades da organização na etapa de produção do documento.

Metadados de preservação é uma expressão que remete a outras funções arquivísticas com implicações em relação à preservação de documentos digitais. Para melhor explicar esse assunto, recorre-se à seguinte citação de Ferreira (2006, p.54): “metainformação de preservação é responsável por reunir, junto do material custodiado, informação detalhada sobre a sua proveniência, autenticidade, actividades de preservação, ambiente tecnológico e condicionantes legais".

Já quanto aos metadados de preservação no tocante ao acesso, esses se apresentam como mais um elemento facilitador para a identificação e a recuperação de sistemas, permitindo o entendimento dos sistemas e contexto dos documentos de arquivo e das demais informações a eles relacionadas.

Um importante documento foi elaborado pela Câmara Técnica de Documentos Eletrônicos do Conselho Nacional de Arquivos. Trata-se do Modelo de Requisitos para Sistemas Informatizados de Gestão Arquivística de Documentos - e-ARQ Brasil -, que enfatiza o importante legado de documentos em formato digital no contexto da arquivologia, bem como da área de tecnologia da informação. Seus elaboradores definem o documento arquivístico e o documento digital a partir de uma análise com vistas a soluções que venham a suprir as dificuldades trazidas por esse suporte. A respeito do referido documento, que também leva em consideração os fundamentos da diplomática, Duranti afirma que:

Essa capacidade dos registros documentais de capturar os fatos, suas causas e consequências, e de preservar e estender no tempo a memória e a evidência desses fatos, deriva da relação especial entre os documentos e a atividade da qual eles resultam, relação essa que é plenamente explorada no nível teórico pela diplomática e no nível prático por numerosas leis nacionais (DURANTI, 1994, p.50).

Ainda no tocante à diplomática, no viés arquivístico, Rondinelli (2005, p.56) diz que: “A análise diplomática de um documento arquivístico pressupõe uma relação entre a palavra e o mundo, o que significa buscar entender o mundo através do documento".

Rondinelli (2005) ainda se refere aos elementos constitutivos de um documento para uma análise diplomática, onde se destaca o elemento conteúdo que, no caso, se entende poder aplicar ao sistema de registro de projetos:

[...] é a mensagem transmitida pelo documento. Conforme dito anteriormente, para existir o documento arquivístico tem que estar afixado num suporte. Isso quer dizer que dados contidos em bases de dados dinâmicas, isto é, que mudam constantemente, não podem ser considerados documentos arquivísticos. Para tanto, esses dados teriam que ser reunidos e seu conteúdo, devidamente articulado, fixado num suporte (RONDINELLI, 2005, p.56). 
No e-ARQ Brasil, são estabelecidos os requisitos básicos para o agente produtor e/ou receptor de documentos no âmbito do Sistema de Gestão Arquivística de Documentos - SIGAD.

Em relação ao SIGAD, e especificamente no requisito segurança, cabe destacar o item Trilhas de Auditoria, que se constitui em um fator determinante no enfoque que se pretende abordar neste trabalho, visto que o item segurança está associado diretamente às possibilidades de comprovação dos registros e das alterações ocorridas em relação a um documento ao longo de sua criação, assim como de seu armazenamento e preservação.

A questão de segurança e preservação, no que tange às propriedades significativas de documento digital, com forte impacto na questão da consistência das informações arquivísticas que fazem parte do banco de dados, tem a seguinte implicação, conforme Ferreira:

A definição das propriedades significativas de um objecto digital influencia directamente a forma como este deverá ser preservado. Quanto maior for o número de propriedades significativas, maiores serão os requisitos relativamente à infra-estrutura tecnológica necessária para suportar a preservação (FERREIRA, 2006, p. 52).

\section{Situações que permeiam a arquivística}

As considerações sobre autenticidade também estão expressas sob a estruturação de normas, através da organização International Organization for Standardization- ISO n. 15.489-1 -, onde são tratados os requisitos de gestão de documentos de arquivo.

O desenvolvimento de sistemas de arquivo exige uma versatilidade do arquivista quanto a sua relação com outros profissionais envolvidos na produção documental. E, nesse aspecto, a Norma ISO n. 15.489-1 trata, de forma expressa, das questões políticas e dos requisitos necessários para uma eficiente gestão documental.

Um elemento que reforça o valor do documento de arquivo são os metadados, a respeito do qual a Norma ISO n. 15.489-1, enfocando a gestão de documentos, define: "Informação que descreve o contexto, conteúdo e estrutura dos documentos de arquivo e da sua gestão ao longo do tempo". Atualmente, a ISO está em fase de elaboração de uma nova série, a 30300, que tem o propósito de atender de maneira mais eficaz as normas que tratam de gestão de documentos de arquivo como a própria 15.489-1, conforme Ruesta (2012).

A série ISO 30300 traz os fundamentos e o vocabulário para a implantação do Sistema de Gestão de Documentos para Arquivo (SGPDA), proposto nessa mesma norma. Salienta-se que a definição de sistema de gestão, no contexto dessa norma é:

O conjunto de elementos inter-relacionados ou que interagem numa organização com o fim de estabelecer políticas e objetivos, bem como os processos para os 
alcançar. Quando falamos de Sistema de gestão para documentos de arquivo (SGPDA), estamo-nos a referir a esse conjunto de elementos relativos aos documentos (RUESTA, 2012, p.8).

Essa norma, ISO 30300, enfatiza a necessidade do comprometimento da alta direção na sua implementação. Ainda com relação à norma ISO da série 30300, esta trata do "alinhamento das técnicas e dos processos documentais com a metodologia dos sistemas de gestão" (RUESTA, 2012, p.6). A proposição do sistema de gestão para documentos de arquivo SGPDA objetiva contribuir para a implementação do processo, de qualidade e de segurança, ou seja: "Assegurando que se crie, gere e se torne acessível, durante todo o tempo que seja necessário, informação fidedigna e fiável que constitua evidência das atividades realizadas dentro de um sistema de gestão" (RUESTA, 2012, p.15).

Quanto à norma ISO 30301, a mesma encontra-se em fase de elaboração e trará os requisitos para o funcionamento do Sistema de gestão de documentos que deve ser estruturado em qualquer organização que tenha como meta o melhoramento de seus processos, independentemente de ser uma instituição com funções arquivísticas ou não.

Quanto à fidedignidade, essa é a qualidade atribuída ao documento referente à sua capacidade de servir de prova digna de crédito.

Outra característica importante do documento de arquivo é a sua integridade, visto que esse deverá ser completo e inalterado, sob pena de, caso não seja observada essa característica, ele tornar-se inconsistente como informação para a organização/usuário no momento em que for preciso recorrer a esse documento para obter informações de seu interesse.

Associa-se à característica do documento de arquivo a "integridade". A LAI, no artigo $7^{\circ}$, assegura o acesso à informação em sua completude e expressa o direito do cidadão em obter informações, conforme o inciso IV do mesmo artigo, "informação primária, íntegra, autêntica e atualizada". No artigo $6^{\circ}$, inciso II, observa-se que cabe ao agente público zelar pela: "proteção da informação, garantindo-se sua disponibilidade, autenticidade e integridade".

Cabe destacar o que Lara (2001, p.7) diz a respeito do interesse do usuário que busca a informação: "[...] para haver informação é preciso que ela faça sentido para alguém, ou seja, que exista algum nível de compartilhamento a partir do qual se estabeleça um vínculo para a interpretação e o sentido".

Portanto, o objetivo de um sistema de arquivo é manter os requisitos básicos que credenciarão os documentos nele armazenados a se tornarem aptos para responder às necessidades dos usuários de uma forma isenta, o que se dá através de uma adequada gestão de documentos. Cabe, nesse sentido, enfatizar o conceito de Arquivologia que, segundo o Dicionário Brasileiro de Terminologia Arquivística - DBTA -, é a disciplina que estuda as funções do arquivo (local) e os princípios e técnicas a serem observados na produção, organização, guarda, preservação e utilização dos arquivos (documentos) (BRASIL, 2005, p.29).

De outra parte, considera-se a questão dos documentos arquivísticos quanto a sua natureza orgânica e funcional. Quanto a esse aspecto, Silva assim se refere:

A natureza orgânica da informação arquivística se relaciona ao fato de que tal informação é produzida a partir de uma estrutura organizacional com setores, 
departamentos e divisões interdependentes com objetivos comuns, e a natureza funcional diz respeito às diferentes funções e usos dessas informações produzidas (SILVA, 2008, p.45).

O profissional arquivista deve ter uma visão ampla de todos as nuances que envolvem a organização. Deve, também, ter uma visão estratégica e gerencial das implicações e do(s) fluxo(s) dos documentos na organização.

Com relação às responsabilidades do profissional arquivista associadas à LAI, essa o incumbe de observar rigidamente o trato legal do acesso a informações, considerando que, até então, não se contava com uma legislação específica e detalhada. Tal rigor se observa em toda a lei, mas em especial, no capítulo II "do acesso à informação e da sua divulgação", onde se asseguram, entre outras obrigações, as associadas a projetos, considerando sua amplitude e especificidade. Conforme visualizado no artigo $6^{\circ}$, inciso II, a "gestão transparente da informação" é aquela que propicia amplo acesso a ela e a sua divulgação. A LAI estabelece excepcionalidades em relação a informações sobre projetos, conforme o artigo $6^{\circ}$, inciso VII, $\S 1^{\circ}$, que anuncia: "o acesso à informação [...] não compreende as informações referentes a projetos de pesquisa $\mathrm{e}$ desenvolvimento científicos ou tecnológicos cujo sigilo seja imprescindível à segurança da sociedade e do Estado".

Associa-se à excepcionalidade o que Rodrigues (2009, p.9) enfatiza quanto à importância da atuação do arquivista, quando diz que: "O arquivista deve ser capaz de analisar criticamente a realidade que se coloca à luz de conhecimentos teóricos e de atuar com competência de modo autônomo e consequente".

Em relação às responsabilidades das autoridades públicas, cita-se o artigo $26^{\circ}$, o qual associa a participação do profissional arquivista, que é/será de suma importância à implementação da LAI no âmbito destas instituições: "As autoridades públicas adotarão as providências necessárias para que o pessoal a elas subordinado hierarquicamente conheça as normas e observe as medidas e procedimentos de segurança para tratamento de informações sigilosas". Percebe-se que o profissional arquivista deverá ter uma atuação intensa na tarefa de disseminar e esclarecer os demais profissionais sobre as questões de segurança que envolvem os documentos sigilosos.

Em se tratando de uma instituição pública, como é a UFSM, a questão do acesso às informações do banco de dados da instituição não era prioridade dos seus responsáveis, sendo que a falta de recursos era a justificativa mais usada. Assim, o acesso às informações arquivísticas por parte do cidadão, no que se refere a serviços on-line, dependia das prioridades da instituição e da forma como essas informações arquivísticas eram nela produzidas e mantidas. Nesse momento, cabe um marco divisor, considerando a situação anterior à LAI e após o início de sua vigência, cujo destaque é voltado ao artigo $8^{\mathrm{o}}$ : "É dever dos órgãos e entidades públicas promover, independentemente de requerimentos, a divulgação em local de fácil acesso, no âmbito de suas competências, de informações de interesse coletivo ou geral por eles produzidas ou custodiadas".

A lei trata, de forma específica, da divulgação de informações pertinentes a projetos que deverão ser, no mínimo, informados, conforme o artigo $8^{\circ}$, inciso $\mathrm{V}$, os: "dados gerais para o acompanhamento de programas, ações, projetos e obras de órgãos e entidades"; a lei ainda expressa, através desse mesmo artigo, no inciso VI, $\S 2^{\circ}$, que: "os órgãos e entidades públicas deverão utilizar todos os meios e instrumentos legítimos de que dispuserem e principalmente a divulgação em sítios oficiais da rede mundial de computadores (internet)". Além do mais, observa-se no artigo $8^{\circ}, \S 3^{\circ}$, I que os sítios (web) "devem conter ferramenta de pesquisa de 
conteúdo que permita o acesso à informação de forma objetiva, transparente, clara e em linguagem de fácil compreensão".

A respeito da política pública de informação referente à preservação da informação arquivística governamental, Silva faz a seguinte consideração:

As atenções direcionadas à preservação dos documentos de arquivo apenas quando considerados "históricos" e integrados ao "patrimônio arquivístico" devem voltar-se para a preservação da informação arquivística de uso corrente, administrativo, funcional e estratégico na expectativa de atender, no presente e no futuro, a sociedade (SILVA, 2008, p.114).

Quanto à preservação da informação, cita-se a norma da ABNT 15.472, o Modelo de referência para um sistema aberto de arquivamento de informação (SAAI), aberto no sentido de discussão pública sobre a elaboração da norma. Essa norma pode ser aplicada a qualquer tipo de arquivo, principalmente em instituições que tenham como responsabilidade a disseminação de informações por longo prazo. E também as instituições que trabalham com informações temporárias, mas que, devido a mudanças provocadas por novas tecnologias, mudanças de foco da instituição, assim como outros motivos, necessitem manter as informações por longo prazo. A norma se justifica, também, pelo fato de muitas organizações se depararem com um volume elevado de informações digitais que, até então, não seriam típicas dessas instituições, mas a partir dessa situação, passaram a ter que assumir algumas funções arquivísticas.

Constata-se que as mudanças no universo arquivístico acontecem praticamente na mesma velocidade das inovações em TI, assim como as mudanças do padrão comportamental no homem contemporâneo.

\section{Pós-Custodial}

A contemporaneidade das atividades arquivísticas inclui também um novo paradigma que é o da era pós-custodial. Para introduzir esse tema, cita-se:

O técnico, guardador de documentos que, na rectaguarda, esperava discretamente que a entidade orgânica produtora de informação lhe remetesse aqueles suportes documentais que deixavam de ter uso administrativo corrente terá de, na chamada "era pós-custodial", passar a estar na linha da frente, isto é, junto da produção da informação [...] (FERNANDA, 2005, p.9).

Esta citação evidencia um paradigma que ainda está em construção e que induz uma mudança de postura do arquivista, ou seja, o profissional deixa de ter uma atuação passiva e passa a ter uma atuação proativa. É também exigida desse profissional uma interação com outros profissionais, 
principalmente da área de TI, assim como com profissionais de outras áreas que atuam na organização.

Tem-se outra citação que reforça a quebra do paradigma custodial que é:

A simbiose entre a informação e a tecnologia digital veio pôr em causa a noção estática e duradoira de "documento" (tendencialmente identificado com mensagens registradas num suporte papel) como conceito operatório e como objecto de estudo e marcou a entrada dos arquivos e da Arquivística na chamada "era pós-custodial" (FERNANDA, 2005, p.7).

Recorre-se a Silva (2010) para contextualizar a transição dos paradigmas e, para isso, cita-se:

E precisa, ainda, de uma metateoria explicativa, baseada em dois paradigmas essenciais: o custodial, patrimonialista, historicista e tecnicista, que surge a partir do séc. XVIII até à Era da Informação em que vivemos; e o pós-custodial, informacional e científico, que tenderá a formatar o modo de ver, de pensar e de agir de gerações de cientistas e profissionais da informação, ao longo do séc. XXI [...]. A transição de um paradigma para outro não ocorre por ruptura, é gradual, tensa e está em curso (SILVA, 2010, p.10).

Tem-se, nos estudos de Terry Cook, uma ênfase no princípio de proveniência dos documentos sob o enfoque funcional, considerando a diversidade de cenários em que esses documentos podem ser utilizados dentro da organização. Sendo assim: "A nova proveniência funcional refletiria a realidade dos documentos em seus contextos e histórias inter-relacionadas, em constante evolução, abrindo ao invés de se fechar em ordens hierárquicas fixas" (COOK, 2012, p.146). Cook evoca a flexibilidade da informação/documento, ou seja: o dinamismo das trocas das releituras de outras associações, produzindo outros documentos, permite outros fazeres.

\section{Curadoria digital}

Outra questão que se insere no universo arquivístico contemporâneo é a curadoria digital e, para tanto, cita-se:

Ainda que seja um conceito em evolução, já está estabelecido que a curadoria digital envolve a gestão atuante e a preservação de recursos digitais durante todo o ciclo de vida de interesse do mundo acadêmico e científico, tendo como perspectiva o desafio temporal de atender a gerações atuais e futuras de usuários (SALES; SAYÃO 2012, p.125). 
Destaca-se a gestão e a preservação que envolvem requisitos e normativas associadas à consistência das informações arquivísticas em suporte digital por longo prazo.

A curadoria digital também inclui a gestão de grandes conjuntos de dados para uso diário, assegurando, por exemplo, que eles possam ser pesquisados e que continuem viáveis, ou seja, capazes de serem lidos e interpretados. Nessa perspectiva, a ideia de curadoria digital estende-se para além do controle do repositório que arquiva os recursos e envolve a atenção do criador do conteúdo e dos usuários futuros (SALES; SAYÃO 2012, p.126).

O estágio das discussões acadêmicas sobre curadoria digital faz-se apresentar de forma desafiadora, tendo como referência a publicação do e-book Curadoria Digital e o Campo da Comunicação, proposto pelo grupo de pesquisa COM + - Grupo de Pesquisa em Comunicações e Mídias da ECA-USP - Escola de Comunicação e Artes da Universidade de São Paulo -, onde a conclusão principal foi que "a curadoria digital ainda não possui uma compreensão uniforme de seus significados no campo da Comunicação” (CORRÊA, 2012, p.9).

Portanto, frisa-se que os documentos produzidos e mantidos no SIE, no módulo de registros de projetos, assim como nos demais módulos, devem ser tratados de forma austera, onde se destaca o que diz Rondinelli (2005, p.65): "Quanto mais rígidas, detalhadas, as regras e o estabelecimento de rotinas terão como resultado mais fidedignidade". Isso faz com que o estabelecimento de regras garanta a idoneidade do SIE.

Rondinelli (2005) ainda diz que para a obtenção dessa condição, idoneidade, a mesma pode ser garantida através recursos/ferramentas que viabilizem a prevenção e a verificação dos documentos gerados pelo sistema.

\section{Considerações finais}

Como já foi relatado, o SIE constitui-se como um sistema de informação da UFSM, no qual o sistema de registro de projetos está inserido. Dessa forma, considerando as observações operacionais e os estudos teóricos sobre os documentos arquivísticos digitais que compõem a produção institucional da UFSM, os projetos desenvolvidos no âmbito do CAL e o universo arquivístico de uma instituição federal de ensino superior, concernente aos conhecimentos teóricos e normativos, esses sob o efeito da Lei de Acesso à Informação e de enfoques que permeiam à arquivística, tem-se a ponderar:

- a importância para as instituições públicas e para os profissionais arquivistas, assim como para a sociedade, a promulgação da Lei $\mathrm{n}^{\circ} 12.527$, de acesso à informação, lei essa que, conforme seu artigo $2^{\circ}$, regra o acesso às informações de órgãos públicos [...];

- que a instituição pública - UFSM - está comprometida, por força constitucional - Constituição Federal de 1988, no seu artigo 216, parágrafo $2^{\circ}$-, com a gestão da documentação e a sua consulta (acesso); 
- que o banco de dados da instituição constitui importante fonte de consulta e de pesquisa, especialmente com relação aos vários tipos de projetos e também ao volume e à diversidade das informações nele contidos, podendo servir como referência para outras instituições e demais interesses da sociedade;

- as normas, como a série ISO 30300 e ABNT, abrangem, entre outras, as questões de segurança e de sistemas que dão suporte às instituições que tratam com funções arquivísticas em seus processos;

- o enfoque pós-custodial e o da curadoria digital são temas contemporâneos que também fazem parte do cotidiano das instituições públicas que tratam com informações e têm sob sua responsabilidade a viabilização idônea do acesso às informações.

Conclui-se que o engendramento arquivístico é uma constante em todas as instituições públicas e, para isso, conta com um arcabouço teórico, normativo, institucional e legal para garantir o direito de acesso do cidadão/sociedade a informações confiáveis.

Institucionalmente, a UFSM tem o compromisso de divulgar e facilitar o acesso do que é produzido em termos de ensino, pesquisa e extensão à comunidade acadêmica assim como à sociedade.

Portanto, espera-se que este trabalho sirva como uma contribuição aos responsáveis pelo sistema, envolvidos com as informações arquivísticas, e que eles concentrem esforços no sentido de que o referido sistema apresente as informações arquivísticas alusivas a projetos de forma consistente, atendendo às normas e critérios das áreas envolvidas com o sistema.

Artigo recebido em 02/08/2013 e aprovado em 02/10/2013

\section{Referências}

BELLOTTO, H. L. Arquivos permanentes: tratamento documental. 4.ed. Rio de Janeiro: FGV, 2007.

BRASIL. Lei $\mathbf{n}^{\mathbf{8}} \mathbf{8 . 1 5 9}$, de 11 de Janeiro de 1991. Disponível em: <http://www.planalto.gov.br/ccivil_03/leis/L8159.htm>. Acesso em: 5 jun. 2013.

Decreto $\mathbf{n}^{\mathbf{0}} \mathbf{7 8 4 5}$, de 14 de novembro de 2012. Disponível em: <http://www.planalto.gov.br/ccivil_03/_ato2011-2014/2012/Decreto/D7845.htm>. Acesso em: 5 jun. 2013.

Lei no 12.527, de 18 de Novembro de 2011. Disponível em: http://www.planalto.gov.br/ccivil_03/_ato2011-2014/2011/lei/112527.htm. Acesso em: 5 jun. 2013.

COOK, T. Entrevista - Terry Cook. INCID, Ribeirão Preto, v. 3, n. 2, p. 142-156, jul./dez. 2012. 
CONARQ - Conselho Nacional de Arquivos. Câmara Técnica de Documentos Eletrônicos. Modelo de requisitos para sistemas informatizados de gestão arquivística de documentos: e-ARQ Brasil. $2006 . \quad$ Disponível em: <http://www.conarq.arquivonacional.gov.br/Media/publicacoes/earqbrasilv1.pdf>. Acesso em: 8 out. 2008 .

CORREA, L. N. S. Curadoria digital e o campo da comunicação. São Paulo: ECA/USP, 2012. Disponível em: <issuu.com/grupo-ecausp.com/docs/ebook_curadoria_digital_usp>. Acesso em: 5 jul. 2013.

DURANTI, L. Estudos históricos, RJ, v.7, n.13, 1994. Disponível em: <http://www.cpdoc.fgv.br/revista/arq/134.pdf>. Acesso em: 10 out. 2008.

FERREIRA, M. Introdução à preservação digital - conceitos, estratégias e actuais consensos. Guimarães, Portugal: Escola de Engenharia da Universidade de Minho, 2006.

INTERNATIONAL COUNCIL ON ARCHIVES. Committee on currente records in a electronic environment. Electronic records: workbook for archivist. Paris (France): ICA, 2005. (ICA Studies 16). Disponível em: <http://www.ica.org/sites/default/files/ICAEstudo16_PT_4.pdf>. Acesso em: 8 out. 2008.

ISO - INTERNATIONAL ORGANIZATION FOR STANDARDIZATION. ISO 154891:2001. Information and documentation - Records Management. Part 1: General. /s.n./ 2001. Disponível em: <www.tavanir.org.ir/tech-doc/nezam/iso_15489-1.pdf>. Acesso em: 5 jun 2013.

LARA, M.L.G. de. O unicórnio (o rinoceronte, o ornitorrinco...), a análise documentária e a linguagem documentária. DataGramaZero: revista de ciência da informação, v.2, n.6, dez. 2001. Disponível em: <www.dgz.org.br>. Acesso em:

JARDIM, J. M. Sistemas e políticas públicas de arquivos no Brasil. Niterói- RJ: EDUFF, 1995.

PAES, M. L. Arquivo: teoria e prática. 3. ed. Rio de Janeiro: FGV, 1997.

RODRIGUES, A. C. Diplomática contemporânea como fundamento para a construção de metodologias em arquivística: a identificação de tipologias documentais. ENCONTRO NACIONAL DE PESQUISA EM CIÊNCIA DA INFORMAÇÃO, 10. João Pessoa, 2009. Disponível em: <http://dci2.ccsa.ufpb.br:8080/jspui/handle/123456789/481>. Acesso em: 2 abr. 2011.

RONDINELLI, R. C. Gerenciamento arquivístico de documentos eletrônicos: uma abordagem teórica da diplomática arquivística contemporânea. 4.ed. Rio de Janeiro: FGV, 2005. $160 \mathrm{p}$.

RIBEIRO, F. Os arquivos na era pós-custodial: reflexões sobre a mudança que urge operar. /s.n./ 2005. p.129-133. Disponível em: <repositorio-aberto.up.pt/handle/10216/14000>. Acesso em: 5 jul. 2013.

RUESTA, C. B. Série ISO 30300: Sistema de gestão para documentos de arquivo. Lisboa: ABD, 2012.

SALES, L. F.; SAYÃO, L. F. O impacto da curadoria digital dos dados de pesquisa na 
comunicação científica. Encontros Bibli, Florianópolis, v. 17, n. esp. 2 - III SBCC,p.118135, 2012. Disponível em: <eprints.rclis.org/18373/>. Acesso em: 5 jul. 2013.

SCHELlENGERB, T. R. Arquivos modernos: princípios e técnicas. Rio de Janeiro: FGV, 1974.

SILVA, A. M. Mediações e mediadores em Ciência da Informação. Prisma.com, Porto, n.9, p.110, 2010. Disponível em: 〈http://revistas.ua.pt/index.php/prismacom/article/view/700/pdf >.

Acesso em: 5 jul. 2013.

SILVA, S. C. A. A preservação da informação arquivística governamental. Rio de Janeiro: AAB/FEPERJ, 2008.

\section{Banco de dados:}

Universidade Federal de Santa Maria, SIE - Sistema de Informações para o Ensino. 